\title{
As Mulheres nas Prisões Brasileiras: algumas considerações
}

\section{Women in Brazilian Prisons: some considerations}

\author{
Ivaneide Nunes Paulino Grizente \\ Programa de Pós-Graduação em História das Ciências e das Técnicas e \\ Epistemologia (HCTE), Universidade Federal do Rio de Janeiro (UFRJ). \\ neideufrj@hoitmail.com \\ orcid.org/0000-0002-4370-3430

\section{Regina Maria Macedo Costa Dantas} \\ Programa de Pós-Graduação em História das Ciências e das Técnicas e \\ Epistemologia (HCTE), Universidade Federal do Rio de Janeiro (UFRJ). \\ regina@hcte.ufrj.br \\ orcid.org/0000-0001-9782-2008
}

\begin{abstract}
Resumo. O presente estudo, recorte de investigação de doutoramento, tem como objetivo, descrever as condições das mulheres nas prisões brasileiras, e discutir a sobrevivência das crianças que nascem nas prisões. A base inicial, é o elevado número de mulheres presas por tráfico de drogas, em consequência de seus relacionamentos amorosos. $\mathrm{O}$ estudo restrito a pesquisas bibliográficas apurou que as presidiárias são em grande maioria, jovens, negras e mães. Esta última, aponta para um problema grave - o futuro e condições psicossociais das crianças que nasceram enquanto suas mães estão presas. $O$ estudo conclui que a condição de gênero não é levada em conta por ocasião da prisão, mesmo quando grávida. Chamamos atenção também para os danos causados às crianças que nasceram de mães presidiárias.
\end{abstract}

Palavras-chave: Mulheres. Penitenciárias. Tráfico de drogas.

Abstract. The present study, part of a doctoral research, has as its General Objective, to describe the conditions of women in Brazilian prisons, and to discuss the survival of children who are born in prisons. The initial basis is the high number of women arrested for drug trafficking as a result of their love relationships. The study restricted to bibliographic research found that the majority of women prisoners are young, black and mothers. The latter points to a serious problem - the future and psychosocial conditions of children who were born while their mothers are in prison. 
The study concludes that gender is not taken into account when imprisoned, even when pregnant. We also draw attention to the damage done to children born to prison mothers.

Keywords: Women. Penitentiary. Drug trafficking.

Recebido: 01/10/2018 Aceito: 27/10/2018 Publicado: 05/11/2018

\section{Introdução}

Existe no Brasil atualmente, um cenário altamente preocupante: o índice de mulheres encarceradas, que de acordo com dados do Relatório de Informações Penitenciárias INFOPEN, até o ano de 2016, 42.355 mulheres se encontram presas.

Isto significa $656 \%$ a mais em relação ao total registrado no início dos anos 2000 , que apresentava números em torno de 6 mil. Esses dados, colocam o Brasil na terceira posição em relação a maior população carcerária feminina do mundo, ficando atrás apenas dos Estados Unidos e Tailândia.

Ainda de acordo com o Relatório INFOPEN, as mulheres presas apresentam o seguinte perfil: são jovens, $62 \%$ são negras, $74 \%$ mães e $45 \%$, apesar de privadas de liberdade, ainda estão sem julgamento. Analisando esse perfil, é possível perceber que o maior índice é o de mulheres com filhos, $74 \%$ dessas mulheres, são mães, e jovens, e isso implica dizer que existem um número alarmante de crianças cujas mães estão presas.

A partir desse cenário, tentaremos pensar o quotidiano de mulheres que se encontram presas, o que fez emergir o objetivo geral desse estudo, que é descrever as condições das mulheres nas prisões. A partir de um estudo bibliográfico, discutiremos também, como nascem e (sobre) vivem as crianças que vêm ao mundo quando suas mães se encontram presas.

\section{As Cadeias de Mulheres}

O encarceramento feminino só se tornou realidade a partir da década de 1940, até então, a criminalidade não estava relacionada com as mulheres, e inicialmente, elas ocupavam os presídios masculinos. (FREITAS, 2013).

Porém, devido a diversos problemas encontrados com essa não separação, houve no Brasil, a previsão Legal para prisões femininas, por meio do Decreto-lei $n^{\circ} 2.848$, de 7 de dezembro de 1940 que diz:

$\S 2^{\circ}$ As mulheres cumprem pena em estabelecimento especial, ou, à falta, em secção adequada de penitenciária ou prisão comum, ficando sujeitas a trabalho interno. 
Com isso, foi inaugurada a primeira penitenciária exclusiva para mulheres, que nasceu e permaneceu por mais de trinta anos, sob a gestão de um grupo religioso, a Congregação de Nossa Senhora da Caridade do Bom Pastor, que desenvolvia prioritariamente a prática do trabalho doméstico junto às detentas e reforçavam a divisão dos papéis sociais entre mulheres e homens, fortalecendo a domesticação do regime de execução penal (ARTUR, 2011).

Atualmente, o cenário das prisões femininas vem se modificando, e a grande maioria se encontra presa por envolvimento com o tráfico de drogas. Mas, é necessário lembrar que:

A mulher traficante de drogas, assim identificada pelo sistema jurídico-normativo no momento de sua prisão, é também esposa, companheira, namorada, mãe e filha, e desempenha diferentes papéis sociais no seu cotidiano. (COSTA, 2008, p. 22).

Essas considerações nos levam em direção a Bauman (2005), ao percurso histórico da humanidade e as consequências da pós modernidade sendo uma das principais, a construção da "Identidade líquida", esta, para Bauman, se configura como "a chave para o entendimento dessa questão passa pelo desejo de buscar um lugar suficientemente confortável, acolhedor e seguro, mesmo num mundo selvagem, imprevisível e ameaçador" (BAUMAN, 2005, p. 76).

Essa vertente está relacionada com o pensamento de Lipovetsky (1994), quando defende que o consumismo desmedido se destaca cada vez mais na sociedade, porém, isto conduz a um quadro de isolamento e os indivíduos tendem a buscar refúgio numa fictícia felicidade paradoxal, proporcionada pelo consumo, que se torna o vetor da economia, e o que seriam meros desejos, passam a ser necessidades, criando um cenário confuso e incerto.

As Identidades Líquidas, se inserem na perspectiva de uma sociedade consumista, muitas vezes somada a um quadro de desajustamento familiar, e isto talvez seja um dos fatores pelos quais, as mulheres se envolvem com o tráfico de drogas, ou, com homens criminosos.

[...] no universo das mulheres presas como traficantes, e as ações relacionadas às drogas nem sempre estão ligadas ao caráter mercadológico do tráfico, mas, são, na realidade, exercidas em nome das relações afetivas que essas mulheres estabelecem com os homens. (COSTA, 2008, p. 23).

A obra da autora, sugere que a grande maioria das mulheres presas, não traficaram drogas como um meio de sobrevivência, mas o fizeram como condição de manutenção de um relacionamento amoroso.

Isto significa que os fatores como desemprego ou pobreza extrema por si só não justificam essas práticas ilícitas das mulheres presas, mas a principal justificativa reside em questões subjetivas. 
Entretanto, o viés de violência que permeia o tráfico de drogas favorece a criação de representações sociais de caráter pejorativo, representações estas, que atingem o imaginário dos indivíduos de forma que muitas vezes, não condiz com a realidade, sobretudo, porque a maior referência que se tem a esse respeito, é aquela proporcionada através da mídia e de filmes, visão esta, deturpada pelo caráter de dramaturgia que extrapola a realidade, pois esta é a função de um trabalho ficcional e de entretenimento.

Para o mundo lá fora, a gente tá morta, aqui é um túmulo, para as pessoas lá fora, a sociedade fala: preso, bicho! Mas aqui também ensina a gente a sair e ser diferente ${ }^{l}$.

A fala da presidiária demonstra sua consciência sobre a forma pela qual a sociedade as percebem e em qual representação social elas estão inseridas, principalmente depois de conhecerem o mundo das prisões, tudo que envolve a condição de presa, e sobretudo o abandono.

[...] na penitenciária Madre Pelletier, em Porto Alegre, uma agente penitenciária simpática comanda o "tour-cadeia". - E aqui fica o ninho de amor delas -[...] é ali que recebem as visitas íntimas. A carcereira constrangida explica: - Sabe o que é? Quase ninguém usa isso aqui... os homens não vêm visitar. (QUEIROZ, 2017, p. 239).

Baseado no trecho acima, o abandono das mulheres presas fica evidente, e o grande contrassenso é que, conforme já assinalado, as mulheres se encontram presas normalmente, em consequência dos envolvimentos amorosos, e estes, literalmente as abandonam.

Para Varella (2017), existem duas diferenças básicas entre as cadeias masculinas e as femininas: a primeira: o tamanho das filas nos dias de visitas, pois nos presídios masculinos é possível observar as grandes filas que se formam, muitas vezes até desde o dia anterior. Já nos presídios femininos, as filas não existem, pois, as visitas são escassas, e quase nenhuma delas recebem visitas.

[...] A sociedade é capaz de encarar com alguma complacência a prisão de um parente homem, mas a da mulher envergonha a família inteira. Enquanto estiver preso, o homem contará com a visita de um mulher, seja a mãe, esposa namorada, prima ou vizinha, esteja ele num presidio de São Paulo ou a centenas de quilômetros. A mulher é esquecida. (VARELLA, 2017 p. 38).

Isso se deve ao fato de que, via de regra, a mulher ao ser presa, normalmente causa um impacto maior nas famílias, e muitas vezes os familiares a abandonam por vergonha, falta de recursos financeiros para chegarem até o presídio, e o principal motivo: os seus companheiros (as) normalmente são impedidos de irem a um presídio por terem antecedentes criminais, serem procurados, ou também se encontrarem presos.

Mas o fato é que "a gratidão eterna que os criminosos juram para suas amadas expira no exato instante em que elas cruzam os portões da cadeia, ainda que aliciadas por eles." (VARELLA, 2017 p. 214).

\footnotetext{
1 Trecho do documentário "Se eu não tivesse amor". Luciana dos Santos Tavares - Presa na penitenciária Talavera Bruce - Rio de Janeiro (10 anos de reclusão por tráfico de drogas).
} 
Varela (2017, p. 50), afirma: "Na penitenciária, se atendo uma mulher de 25 anos sem filhos, há duas possibilidades: é infértil ou gay." A fala do autor configura uma realidade comum nas periferias das grandes metrópoles, onde gravidez na adolescência é uma realidade cruel que compromete seu futuro e a vida dos pais, uma vez que normalmente, ela abandona a escola para cuidar do filho, e os pais por sua vez, se veem com mais uma criança para sustentar.

Isto configura um mix de pobreza, ignorância, residências em condições inóspitas, alcoolismo, violência doméstica e exposição à marginalidade, cenário este, que se aliado a fraqueza de caráter, se consolida como campo apropriado para a aproximação do tráfico, envolvimento com ex-presidiários, (normalmente reincidentes) ou membro de facções criminosas.

Esse tipo de envolvimento via de regra, proporciona a estas mulheres, ajuda financeira, "proteção", status social e a falsa esperança de uma vida melhor. No entanto, normalmente, o destino delas é a prisão e o abandono.

Queiroz (2017), relata que na Penitenciária Feminina de Guaíba- RS, não há trabalho ou Escola, o banho de sol, é de 1 h 30 por dia, e no restante do tempo, as presas são expostas ao ócio. A disciplina é bastante rígida, e nas áreas internas, elas só circulam algemadas.

No presídio de Guaíba, devido às normas rígidas, são comuns ocorrências de pânico, transtorno de ansiedade, depressão severa, e até surtos psicóticos.

Devido ao rigor aplicado às presas, a psicóloga do presídio atribui às presas o que denominou "institucionalização da pessoa", que é quando o sentimento de pertencimento já está vinculado a cadeia, "Elas incorporaram o aprisionamento como regra e não conseguem sair disso.” (QUEIROZ, 2017, p. 176).

As mulheres são presidiárias, mas também são mulheres, e muitas, são mães, mas este, é um capítulo à parte nas prisões brasileiras, pois há relatos de presas que deram à luz algemadas na cama.

A mulher grávida, ao ser presa, não recebe tratamento diferenciado, e após o nascimento da criança, a mãe volta para a cela e a criança vai para o berçário, mãe e filho se encontram na hora de amamentar, e isso quando a agente se dispõe a conduzir a presa até o berçário. "Tinha só um polícia que me levava, que ele era bonzinho e levava eu. As guardas mulheres não deixavam e o homem que deixava, acredita? Mas não era todo dia não." (Fala da presidiária Gardenia). (QUEIROZ, 2017. p. 77).

As condições sob as quais vivem essas mulheres presas e separadas dos seus filhos, e, por outro lado, como vivem essas crianças sem a presença da mãe, configura um contexto social específico e altamente preocupante para a sociedade.

Tais considerações nos levam em direção aos teóricos da área da Psicologia que defendem a presença da mãe como imprescindível para o desenvolvimento da criança, 
uma vez que a mãe é a base na formação do indivíduo, e as habilidades no traquejo social, familiar e psicológico da criança vêm da mãe.

A figura da mãe dentro do núcleo familiar é tão importante que chega a superar a figura paterna. Até os 3 anos de idade a criança se enxerga como uma extensão da mãe, somente após essa idade é que o pai ganha espaço na personalidade do filho.

Stella (2006), afirma que amargura da privação do vínculo materno pode ter diversas consequências, dentre as quais, a formação e desenvolvimento da saúde mental da criança, podendo comprometer a afetividade e os relacionamentos futuros desta. A autora aponta ainda como consequência dessa privação, possíveis comportamentos agressivos e delinquentes.

\section{Considerações Finais}

O presente trabalho, tomou como premissa inicial, o significativo aumento do número de mulheres presas em consequência do tráfico de drogas, e a constatação de seus envolvimentos com parceiros amorosos já envolvidos com o crime.

A pesquisa bibliográfica realizada revelou que, apesar de algum avanço, as mulheres ao serem presas, não são objeto de qualquer ação ou diferenciação de gênero, inclusive, quando grávidas, não recebem qualquer tipo de distinção no tocante aos procedimentos que envolvem o ato da prisão.

O estudo identifica ainda que a grande parte dos presídios femininos ainda são alheios às características específicas que a condição de gênero supõe às mulheres, como por exemplo, houve relato de mulheres que permaneceram algemadas por ocasião do parto. Além disso, em alguns presídios, são separadas de seus filhos, só mantendo contato no momento da amamentação.

Porém, o mais grave, é que, ao completar seis meses de idade, a criança é separada da mãe, sendo conduzida aos cuidados de um familiar, quando é o caso, ou oferecida para adoção.

Portanto, o que se chama a atenção aqui, é para o futuro dessas crianças, e para a urgência de políticas públicas, no sentido de minimizar os danos causados pela história de vida da mãe, e sobretudo, políticas públicas sociais que visem dirimir as consequências psicológicas de uma separação da mãe, em momento crucial de sua vida.

Por se tratar de um recorte de pesquisa doutoral, foi identificada esta especifica condição da vivência feminina em prisões, para inserir nas agendas das discussões sobre gênero, com o propósito de divulgar a situação das mulheres encarceradas e seus filhos nascidos nas prisões. 


\section{Referências}

AGUIRRE, Carlos. Carcere e Sociedade na America Latina. IN: História das prisões no Brasil Volume 1 - $1^{\text {a }}$ ed. - Rio de Janeiro: Anfiteatro, 2017.

BAUMAN, Zygmunt. Confiança e medo na Cidade. Rio de Janeiro: Editora Zahar, 2005.

, Zygmunt. Identidade entrevista a Benedetto Vecchi. Tradução: Carlos

Alberto Medeiro. Rio de Janeiro. Zahar, 2005.

BRASIL, Ministério da Justiça. Levantamento Nacional de Informações Penitenciárias INFOPEN - junho de 2016.

BRETAS, M.L. O que os olhos não vemm: históra das prisões no Rio de Janeiro. In: História das prisões no Brasil Volume 1 - $1^{\text {a }}$ ed. - Rio de Janeiro: Anfiteatro, 2017.

COSTA, E.C.P. As teias afetivas que envolvem a mulher no tráfico de drogas. 2 ed.rev. e ampl. - Maceió: EDUFAL, 2008.

LIPOVETSKY, G. La era del Vacio: ensayos sobre el individualismo contemporâneo. $7^{\mathrm{a}}$ ed. Barcelona: Editorial Anagrama, 1994.

MAIA, C.N. [et al]. História das prisões no Brasil Volume $1-1^{\mathrm{a}}$ ed. - Rio de Janeiro: Anfiteatro, 2017.

QUEIROZ, Nana. Presos que menstruam. $-7^{\text {a }}$ Ed. - Rio de Janeiro: Record, 2017.

STELLA, Cláudia. Filhos de mulheres presas: soluções e impasses para seus desenvolvimentos. São Paulo: LCTE Editora, 2006. 117p.

VARELLA, Dráuzio. Prisioneiras.- 1 $^{\mathrm{a}}$ ed. - São Paulo: Companhia da Letras, 2017. 


\section{Vídeos}

CHAVES, Geysa. Se eu não tivesse amor - documentário 2008/2009-RJ. Disponível em: https://www.youtube.com/watch?v=TF8S5oGkL-c. Acesso em 13 out 2018. 